\title{
SURGICAL RESULTS IN MALIGNANT GLAUCOMA REFRACTORY TO MEDICAL OR LASER THERAPY
}

\author{
JAMES C. TSAI, KEITH A. BARTON, MICHAEL H. MILLER, PENG T. KHAW and \\ ROGER A. HITCHINGS \\ London
}

\begin{abstract}
SUMMARY
We investigated the surgical results in 25 patients identified with malignant (ciliary block) glaucoma. Four of these patients $(16 \%)$ had successful outcomes following laser treatment alone. Nineteen patients $(\mathbf{7 6} \%)$ underwent microsurgery for glaucoma refractory to conventional medical and/or laser therapy and are the subjects of this study. Core vitrectomy was successful in 4 of 6 pseudophakic patients $(67 \%)$ and in 1 of 4 phakic patients $(25 \%)$. Combined cataract extraction and vitrectomy had a higher success rate in patients undergoing posterior capsulectomy at the time of surgery ( 5 of 6 patients; $83 \%$ ) compared with those patients left with an intact posterior capsular bag ( 1 of 4 patients; $25 \%$ ). Intracapsular cataract extraction was successful in 1 of 2 patients $(50 \%)$. We conclude that surgical vitrectomy in the presence of an intact posterior capsule may preclude the surgical resolution of aqueous misdirection. In eyes with pre-existing cataract, we recommend combined lens extraction, primary posterior capsulectomy and surgical vitrectomy for the surgical management of phakic malignant glaucoma.
\end{abstract}

Malignant glaucoma is a rare and serious complication following intraocular surgery that is characterised by a shallow or flat anterior chamber and an elevated intraocular pressure in the presence of a patent iridotomy. ${ }^{1-4}$ The aetiology is thought to be related to anatomical obstruction of aqueous flow at the anterior hyaloid/zonule-lens/ciliary process interface. Various other terms such as aqueous misdirection syndrome, ciliolenticular glaucoma, ciliary block glaucoma and ciliovitreal block glaucoma have been proposed based on presumed pathophysiological mechanisms.

From: Glaucoma Unit, Moorfields Eye Hospital, London, UK. Dr Tsai is currently affiliated with the Department of Ophthalmology and Visual Sciences, Vanderbilt University School of Medicine, Nashville, USA.

Correspondence to: James C. Tsai, MD, Vanderbilt University Eye Center, 8018 Medical Center East, Nashville, TN 37232-8808, USA
Medical treatment with vigorous cycloplegia, aqueous suppression and dehydration of the vitreous with intravenous or oral hyperosmotic agents is the usual first-line treatment. ${ }^{5,6}$ If medical treatment is unsuccessful, good results have been obtained in aphakic and pseudophakic patients with laser hyaloidotomy or capsulotomy performed with the Nd:YAG laser. ${ }^{7-11}$ In pseudophakic patients, Little and Hitchings ${ }^{10}$ have advocated the positioning of the capsulotomy peripheral to the lens optic to avoid the risk of subsequent blockage of aqueous flow by the juxtaposed optic. Herschler ${ }^{12}$ has also reported the use of the argon laser to treat the ciliary processes via the transpupillary route in aphakic patients with malignant glaucoma.

In cases resistant to medical or laser treatment, surgical treatment is often necessary to correct the aqueous misdirection. Early surgical techniques for this condition included posterior sclerectomy ${ }^{13}$ and lens extraction. ${ }^{14}$ Shaffer ${ }^{15}$ noted the importance of vitreous loss during lens extraction in order for the procedure to be successful. Chandler ${ }^{16}$ described the procedure of deep vitreous aspiration with anterior chamber deepening. More recently, Lynch and colleagues $^{17}$ have advocated pars plana vitrectomy and posterior capsulectomy.

In an attempt to better understand the surgical treatment of malignant glaucoma, we reviewed our surgical results in patients refractory to conventional medical and/or laser therapy.

\section{PATIENTS AND METHODS}

We reviewed the medical records of all patients with malignant glaucoma seen by either of two glaucoma specialists (R.A.H. or M.H.M.) from 1 January 1988 to 31 December 1994. Malignant glaucoma was defined as a shallow or flat central anterior chamber associated with elevated intraocular pressure, intact peripheral iridotomy, forward movement of the iris/ anterior hyaloid face, and posterior misdirection of

Eye (1997) 11, 677-681 (C) 1997 Royal College of Ophthalmologists 
aqueous fluid. Twenty-five patients with malignant glaucoma were identified. Of these 25 patients, 19 $(76 \%)$ underwent surgical intervention for refractory malignant glaucoma and had a minimum of 3 months post-operative follow-up. All 19 patients were diagnosed with malignant glaucoma by either R.A.H. or M.H.M. and were deemed to require surgical intervention to relieve the condition. Only the first eye of 3 patients who developed bilateral malignant glaucoma during the study period was considered in the analysis of surgical outcomes.

Of the 6 patients excluded from the study, 4 had been treated successfully with Nd:YAG hyaloidotomy either through a patent iridectomy or through the pupillary space (in a pseudophakic eye). Another patient had successful resolution of the aqueous misdirection with intensive mydriatic and cycloplegic medical therapy complemented with aqueous suppressants. One additional patient had inadequate surgical follow-up of less than 3 months duration.

The medical records of the remaining 19 patients were reviewed to obtain the following information: demographics; previous ocular surgical history; predisposing risk factors; type of surgical procedure performed; pre-operative and post-operative visual acuities, intraocular pressure and antiglaucoma medications; significant complications; reoperations or additional procedures. Patients were divided into the following surgical subgroups: aphakic or pseudophakic core vitrectomy, phakic core vitrectomy, combined cataract extraction and vitrectomy with primary posterior capsulectomy, combined cataract extraction and vitrectomy with intact posterior capsule, and intracapsular cataract extraction. The above demographic data are summarised in Table I.

Surgical success and failure were defined prior to data analysis. Failure was defined as failure to break the ciliolenticular block, vitrectomy reoperation (or recommendation thereof) or devastating complication. In each surgical subgroup, surgical outcome was determined by the percentage of successful cases and the need for additional procedures (Table II). Given the relatively small numbers of patients enrolled in each subgroup, Kaplan-Meier survival curve analysis of the data was deferred.

\section{RESULTS}

\section{Core Vitrectomy}

Core vitrectomy was performed in a total of 10 patients. The procedure involved removal of cortical

Table I. Individual patient data

\begin{tabular}{|c|c|c|c|c|c|c|c|c|c|}
\hline \multirow{2}{*}{$\begin{array}{l}\text { Patient } \\
\text { no. }\end{array}$} & \multirow{2}{*}{$\begin{array}{l}\text { Age (years/ } \\
\text { ethnicity/sex }\end{array}$} & \multicolumn{5}{|c|}{ Pre-surgical } & \multicolumn{3}{|c|}{ Post-surgical } \\
\hline & & Diagnosis & Lens status & Prior sugery & VA, IOP & Procedure & VA, IOP & $\mathrm{F} / \mathrm{U}$ (months) & Outcome/comments \\
\hline 2. & 75/Cauc/F & POAG & Pseudophakic & CE, Trab & $\mathrm{CF}, 38$ & AV & $6 / 36,16$ & 3 & Success \\
\hline 3. & 64/Cauc/F & $\mathrm{ACG}$ & Pseudophakic & Trab, CE & $6 / 18, \mathrm{NR}$ & AV & $6 / 36,16$ & 5 & Success \\
\hline 4. & 69/Cauc/F & $\mathrm{ACG}$ & Pseudophakic & Surg PI, CE & $6 / 60,27$ & AV & $6 / 9,17$ & 43 & Success $^{\mathrm{a}}$ \\
\hline 5. & 77/Cauc/F & POAG & Pseudophakic & CE, Trab, MI & $6 / 36.40$ & AV & HM, 24 & 1 & Failure $^{\mathrm{a}}$ \\
\hline 7. & 33/Asian/F & ACG & Phakic & Trab & $6 / 5,23$ & PPV & $6 / 12.21$ & 11 & Success $^{\mathrm{a}}$ \\
\hline 8. & 39/Cauc/F & $\mathrm{ACG}$ & Phakic & Trab & $6 / 9.20$ & PPV & $6 / 9,26$ & 0.3 & Failure $^{\mathrm{a}}$ \\
\hline 9. & 44/Cauc/F & $\mathrm{ACG}$ & Phakic & Trab & $6 / 24,48$ & PPV & $6 / 24,50$ & 0.3 & Failure $^{a}$ \\
\hline 10. & 56/Cauc/F & ACG & Phakic & Trab & $6 / 12,32$ & PPV & $6 / 24, \mathrm{NR}$ & 0.5 & Failure $^{a}$ \\
\hline 11. & 63/Cauc/F & ACG & Phakic & Trab & $6 / 60,26$ & Vitlen & $\mathrm{HM}, 18$ & 49 & Success $^{\mathrm{a}}$ \\
\hline 12. & 45/Cauc/F & ACG & Phakic & Trab $\times 2$ & HM, 32 & $\mathrm{CE} / \mathrm{PC} / \mathrm{PPV}$ & $6 / 18.25$ & 16 & Success $^{\mathrm{a}}$ \\
\hline 13. & 27/Cauc/F & ACG & Phakic & Trab & $4 / 36,16$ & CE/PC/AV & HM, 38 & 11 & Failure $^{a}$ \\
\hline 14. & 44/Cauc/F & $\mathrm{ACG}$ & Phakic & Trab & $6 / 9.30$ & $\mathrm{PPV} / \mathrm{CE}$ & $6 / 9,18$ & 13 & Success $^{\mathrm{a}}$ \\
\hline 16. & 75/Cauc/F & ACG & Phakic & Trab & $6 / 18,48$ & $\mathrm{PPV} / \mathrm{CE}$ & $6 / 18,28$ & 3 & Failure $^{a}$ \\
\hline 17. & 71/Cauc/F & ACG & Phakic & Trab & $6 / 36,47$ & $\mathrm{PPV} / \mathrm{CE}$ & $6 / 9,26$ & 2 & Failure $^{a}$ \\
\hline 18. & 82/Cauc/F & PEX & Phakic & None & $6 / 36,15$ & ICCE & $6 / 9,10$ & 65 & Success \\
\hline 19. & 62/Cauc/F & ACG & Phakic & Trab & $6 / 18,17$ & ICCE & $6 / 18,32$ & 15 & Failure $^{a}$ \\
\hline
\end{tabular}

Cauc, Caucasian; F, female; M, male; VA, visual acuity; IOP, intraocular pressure (mmHg); NR, not recorded; F/U, follow-up.

Diagnosis: PEX, pseudoexfoliative glaucoma; POAG, primary open angle glaucoma; ACG, primary angle closure glaucoma.

Prior surgery: CE, cataract extraction; Trab, trabeculectomy; Surg PI, surgical peripheral iridectomy; MI, Molteno implant.

Procedure: PPV, pars plana vitrectomy; AV, anterior vitrectomy; Vitlen, vitreolensectomy; CE, cataract extraction; PC, posterior capsulectomy; ICCE, intracapsular cataract extraction.

${ }^{a}$ Outcome/comments: Patient 4: Developed malignant glaucoma in the other eye. Patient 5: Required repeat vitrectomy with subsequent suprachoroidal haemorrhage in affected eye; developed malignant glaucoma in the other eye. Patient 6: Underwent further Nd:YAG cyclophotocoagulation treatment. Patient 7: Though successful, suffered a vitreous haemorrhage post-operatively which spontaneously cleared. Patient 8: Underwent subsequent lens aspiration/primary posterior capsulorhexis/anterior vitrectomy with successful follow-up of 6 months. Patient 9: Underwent subsequent phacoemulsification/primary posterior capsulorhexis/anterior vitrectomy with successful follow-up of 3 months. Patient 10: Underwent subsequent successful extracapsular cataract exrtaction with planned anterior vitrectomy through a posterior capsulectomy. Patient 11: Resolution of malignant glaucoma; though patient subsequently developed corneal decompensation secondary to bullous keratopathy and had decreased visual acuity. Patient 12: Developed ocular hypertension with early optic disc changes. Patient 13: Underwent trabeculectomy with mitomycin $\mathrm{C}$ for subsequent pressure elevation. Patient 14: Though successful, patient required Nd:YAG posterior capsulotomy on first postoperative day. Patient 15: Patient required repeat vitrectomy and trabeculectomy with 5-fluorouracil. Patient 16: Patient required repeat vitrectomy and trabeculectomy. Patient 17: No resolution of malignant glaucoma; patient underwent subsequent cyclodestruction procedure; developed malignant glaucoma in the other eye. Patient 19: Required revision of right trabeculectomy. 
vitreous in the anterior vitreous cavity through either an anterior or a pars plana approach (no attempt was made to trim the vitreous base). Of 6 patients who were pseudophakic and had posterior chamber intraocular lenses, 4 (67\%) had successful outcomes with a mean follow-up of $14.3 \pm 19.2$ months. Of the 2 patients with failed surgeries, patient 5 required repeat pars plana vitrectomy and enlargement of the peripheral iridectomy at 1 month post-operatively. This patient suffered a limited suprachoroidal haemorrhage at the time of repeat vitrectomy. Patient 6 had continued increased intraocular pressure after pseudophakic vitrectomy and required Nd:YAG cyclophotocoagulation treatment approximately 1 month later.

Only 1 of $4(25 \%)$ phakic patients who had core vitrectomy had successful surgery. Patient 7 had pars plana vitrectomy after developing malignant glaucoma following trabeculectomy. The patient suffered a vitreous haemorrhage post-operatively which cleared spontaneously. At follow-up 10 months later, the patient had a borderline intraocular pressure of $21 \mathrm{mmHg}$ on no medication. Patient 8 had pars plana vitrectomy, but underwent successful lens aspiration/primary posterior capsulorhexis/ anterior vitrectomy approximately 9 days later for elevated intraocular pressure and recurrence of lens touch. Patient 9 had initial success with pars plana vitrectomy, but returned 10 days later with elevated intraocular pressure of $57 \mathrm{mmHg}$. The patient had successful phacoemulsification/primary posterior capsulorhexis/anterior vitrectomy. Patient 10 also had pars plana vitrectomy following the development of malignant glaucoma 1 day post-trabeculectomy. The patient still had persistence of the aqueous misdirection after phakic vitrectomy and required anterior chamber re-formation and revision of trabeculectomy. The patient had subsequent extracapsular cataract extraction with planned anterior vitrectomy through a posterior capsulectomy (see below).

\section{Cataract Extraction/Vitrectomy}

Five of $6(83 \%)$ patients had resolution of their ciliolenticular block following cataract extraction and primary vitrectomy combined with primary posterior

Table II. Results of surgical procedures for refractory malignant glaucoma

\begin{tabular}{lcc}
\hline Surgical procedure & $\begin{array}{c}\text { Success } \\
\text { rate }\end{array}$ & $\begin{array}{c}\text { Percentage } \\
\text { successful }\end{array}$ \\
\hline Pseudophakic vitrectomy & $4 / 6$ & $67 \%$ \\
Phakic vitrectomy & $1 / 4$ & $25 \%$ \\
$\begin{array}{l}\text { Cataract extraction and vitrectomy } \\
\quad \text { posterior capsulectomy) }\end{array}$ & $5 / 6$ & $83 \%$ \\
$\begin{array}{c}\text { Cataract extraction and vitrectomy } \\
\quad \text { (no capsulectomy) }\end{array}$ & $1 / 4$ & $25 \%$ \\
Intracapsular cataract extraction & $1 / 2$ & $50 \%$ \\
\hline
\end{tabular}

capsulectomy. After failure of phakic vitrectomy surgery, patients 8 and 9 subsequently underwent phacoemulsification, primary posterior capsulectomy, and ocutome vitrectomy with successful outcomes. In both these patients, we employed the technique of posterior continuous tear capsulorhexis described by Gimbel and Neuhann. ${ }^{18}$ Patient 10, with initial failure of a phakic vitrectomy, had subsequent resolution of the ciliary block glaucoma following extracapsular cataract extraction with planned anterior vitrectomy through a posterior capsulectomy. Patient 11 underwent successful vitreolensectomy, though the visual acuity at the last follow-up examination was decreased due to corneal decompensation secondary to bullous keratopathy. Patient 12 had a successful outcome following combined extracapsular cataract extraction, posterior capsulectomy, and ocutome vitrectomy through a pars plana approach. At last follow-up 16 months later, there had been no recurrence of the malignant glaucoma though the patient had ocular hypertension with early optic disc changes. Patient 13 had left extracapsular cataract extraction, posterior capsulectomy and limited ocutome vitrectomy. Approximately 11 months later the patient developed uncontrolled intraocular pressure elevation in that eye and underwent trabeculectomy with mitomycin C.

Only 1 of 4 (25\%) patients who underwent combined cataract extraction and vitrectomy in the presence of an intact posterior capsule was classified as a surgical success. Patient 14 had successful combined pars plana vitrectomy and extracapsular cataract extraction with follow-up of 13 months, though she required Nd:YAG posterior capsulotomy on the first post-operative day after a shallow anterior chamber was noted. Patients 15 and 16 required reoperations with vitrectomy and filtration surgery after they were noted to have elevated intraocular pressures with only partial resolution of ciliary block. Finally, patient 17 underwent cyclodestruction surgery following unsuccessful resolution of malignant glaucoma after combined cataract and vitrectomy surgery.

One of 2 patients $(50 \%)$ had successful surgery following intracapsular cataract extraction. Patient 18 had successful surgery with follow-up of 65 months, whereas patient 19 required revision of trabeculectomy approximately 15 months after intracapsular cataract extraction.

\section{DISCUSSION}

In malignant glaucoma, the site of aqueous obstruction appears to be at the level of the zonules/pars plicata. In the aphakic eye with this entity, forward movement of the anterior hyaloid face and apposition of the vitreous body near the ciliary processes 
causes posterior diversion of aqueous humour into the vitreous. Epstein and colleagues ${ }^{19}$ have suggested that increased vitreous volume from this misdirection of aqueous leads to the classical finding of shallowing of the anterior chamber with increased intraocular pressure. A vicious cycle of vitreous expansion with decreased vitreal permeability and subsequent pressure elevation is thus established. In contrast Levene ${ }^{20}$ has postulated that direct lens block is the primary mechanism for malignant glaucoma. In his model, the accumulation of aqueous in the vitreous occurs only as a secondary phenomenon, further increasing the vitreous pressure and aggravating the primary lens block.

In our study vitrectomy alone had a greater success rate in pseudophakic rather than phakic patients. Four of $6(67 \%)$ pseudophakic patients had successful surgery as compared with only 1 of 4 (25\%) phakic patients. Our findings concur with those of Byrnes et al., ${ }^{21}$ which suggested that the success of surgical vitrectomy was greater in the absence of the natural lens. Byrnes and colleagues have also reported a trend toward a higher recurrence of ciliary block (following vitrectomy) in phakic patients as compared with pseudophakic patients. We believe, like Byrnes et al., that these differences may be explained by the greater difficulty in obtaining a complete vitreous removal in a phakic eye. The presence of an intact lens may decrease the likelihood of successful release of the trapped aqueous pocket, especially along the hyaloid face region adherent to the posterior lens capsule.

Our results also suggest a trend towards greater surgical success in patients undergoing primary posterior capsulectomy and surgical vitrectomy at the time of their cataract extraction for malignant glaucoma. Only 1 of 4 (25\%) patients had resolution of their aqueous misdirection following lens extraction and surgical vitrectomy. In our patients undergoing primary posterior capsulectomy at the time of lens extraction and vitrectomy, 5 of $6(83 \%)$ were classified as surgical successes. Our capsulectomy technique involved either performing a posterior capsulorhexis as described by Gimbel and Neuhann ${ }^{18}$ or a capsulectomy with the ocutome vitrectomy device. In each case, the posterior capsulectomy was sufficiently large to allow adequate excision of cortical vitreous through the created opening (however, the actual dimensions of the capsulectomies were not recorded in the operative records).

In their series of 3 patients with posterior chamber intraocular lenses, Lynch and colleagues ${ }^{17}$ reported that a small area of peripheral lens zonules and capsule was excised along with the core vitrectomy. They advocated a posterior capsulectomy for the reestablishment of a direct pathway for aqueous flow through the zonular-capsular region. Momoeda et al. ${ }^{22}$ also reported success with lens removal in five phakic eyes with malignant glaucoma. However, Momoeda and colleagues performed their surgeries via an anterior pars plana vitrectomy combined with intracapsular lens extraction through a corneal incision. In all 5 eyes the anterior chamber regained its normal depth, though 2 patients required additional filtering surgery to control the intraocular pressure.

Based on our clinical experience, vitrectomy for malignant (ciliary block) glaucoma remains a useful adjunct to therapy once medical and laser treatment fail to relieve the aqueous misdirection. Consideration must be given to the apparent lower success rates for primary vitrectomy in phakic eyes as compared with pseudophakic or aphakic eyes. In patients with a pre-existing cataract, lens removal at the time of vitrectomy should be combined with a primary posterior capsulectomy to improve the access to the anterior vitreous and the zonular/pars plicata region. This combined lens extraction/posterior capsulectomy/vitrectomy procedure may be approached by either a pars plana or anterior approach. The former may be accomplished with a pars plana vitrectomy and lensectomy. The latter may be performed either by standard extracapsular cataract extraction or by phacoemulsification with the creation of a posterior capsulectomy (at the time of surgery) through which the anterior vitrectomy is performed.

In conclusion our results suggest that surgical vitrectomy in the presence of an intact posterior capsule may decrease the chance of surgical success. We hypothesise that the inability to excise the core vitreous near the posterior capsule may limit egress of trapped aqueous into the posterior chamber. We recommend that surgical vitrectomy performed concurrently with cataract extraction should include a primary posterior capsulectomy to enable adequate excision of the anterior hyaloid face. Post-operative Nd:YAG laser posterior capsulotomy may not allow for the adequate drainage of the loculated aqueous pocket. In our view the definitive surgical treatment of phakic malignant glaucoma should incorporate lens extraction with primary posterior capsulectomy and surgical vitrectomy.

This work was supported in part by a grant from Research to Prevent Blindness and the International Glaucoma Association.

Key words: Malignant glaucoma, Aqueous misdirection, Ciliary block, Surgical vitrectomy.

\section{REFERENCES}

1. Luntz MH, Rosenblatt M. Malignant glaucoma. Surv Ophthalmol 1987;32:73-93.

2. Levene RZ. Current concepts of malignant glaucoma. Ophthalmic Surg 1986;17:515-20. 
3. Tomey KF, Senft SH, Antonios SR, Shammas IV, Shihab ZM, Traverso CE. Aqueous misdirection and flat chamber after posterior chamber implants with and without trabeculectomy. Arch Ophthalmol 1987;105: 770-3.

4. Zaltas MM, Schuman JS. Malignant glaucoma: theory and therapy, from past to present. Semin Ophthalmol 1994;9:243-7.

5. Chandler PA, Grant WM. Mydriatic-cycloplegic treatment in malignant glaucoma. Arch Ophthalmol 1962; 68:353.

6. Kolker AE, Hetherington J. Procedures to break pupillary and ciliary block. In: Becker-Shaffer's diagnosis and therapy of glaucomas. St Louis: CV Mosby, 1983:444-5.

7. Epstein DL, Steinert RF, Puliafito CA. Neodymium: YAG laser therapy to the anterior hyaloid in aphakic malignant (ciliovitreal block) glaucoma. Am J Ophthalmol 1984;98:137-43.

8. Starita RJ, Klapper RM. Neodymium:YAG photodisruption of the anterior hyaloid face in aphakic flat chamber: a diagnostic and therapeutic tool. Int Ophthalmol Clin 1985;25:119-23.

9. Brown RH, Lynch MG, Tearse JE, et al. NeodymiumYAG vitreous surgery for phakic and pseudophakic malignant glaucoma. Arch Ophthalmol 1986;104: 1464-6.

10. Little BC, Hitchings RA. Pseudophakic malignant glaucoma: $\mathrm{Nd}$ :YAG capsulotomy as primary treatment. Eye 1993;7:102-4.

11. Little BC. Treatment of aphakic malignant glaucoma using Nd:YAG laser posterior capsulotomy. $\mathrm{Br} \mathrm{J}$ Ophthalmol 1994;78:499-501.
12. Herschler J. Laser shrinkage of the ciliary processes: a treatment for malignant (ciliary block) glaucoma. Ophthalmology 1980;87:1155-9.

13. Weber PA. Die Ursache des Glaucoms. Arch Ophthalmol 1877;23:1.

14. Rheindorf DR. Ueber Glaukom. Klin Monatsbl Augenheilkd 1887;25:148-72.

15. Shaffer RN. The role of vitreous detachment in aphakic and malignant glaucoma. Trans Am Acad Ophthalmol Otolaryngol 1954;58:217.

16. Chandler PA. A new operation for malignant glaucoma: a preliminary report. Trans Am Ophthalmol Soc 1964;62:408.

17. Lynch MG, Brown RH, Michels RG, et al. Surgical vitrectomy for pseudophakic malignant glaucoma. Am J Ophthalmol 1986;102:149-53.

18. Gimbel HV, Neuhann T. Development, advantages, and methods of the continuous circular capsulorhexis technique. J Cataract Refract Surg 1990;16:31-7.

19. Epstein DL, Hasimoto JM, Anderson PJ, Grant WM. Experimental perfusions through the anterior and vitreous chambers with possible relationships to malignant glaucoma. Am J Ophthalmol 1979;88: 1078-86.

20. Levene RZ. A new concept of malignant glaucoma. Arch Ophthalmol 1972;87:497-506.

21. Byrnes GA, Leen MM, Wong TP, Benson WE. Vitrectomy for ciliary block (malignant) glaucoma. Ophthalmology 1995;102:1308-11.

22. Momoeda S, Hayashi H, Oshima K. Anterior pars plana vitrectomy for phakic malignant glaucoma. Jpn J Ophthalmol 1983;27:73-9. 